Revista Destaques Acadêmicos, Lajeado, v. 12, n. 3, 2020. ISSN 2176-3070

DOI: http://dx.doi.org/10.22410/issn.2176-3070.v12i3a2020.2601

http://www.univates.br/revistas

\title{
COMPORTAMENTO ADOTADO POR ESTUDANTES DE UMA ESCOLA PÚBLICA MATO-GROSSENSE FRENTE ÀS CONDIÇÕES DE SANEAMENTO BÁSICO PARA EVITAR VERMINOSES
}

\author{
Monica Strege Médici ${ }^{1}$, Milena Macaiewski Ferreira ${ }^{2}$, Marcelo Franco Leão ${ }^{3}$
}

Resumo: Higiene pessoal e condições adequadas de saneamento básico podem ser determinantes para evitar problemas urbanos que afetam a qualidade de vida da população, a exemplo das verminoses. Esse estudo teve como objetivo identificar a situação e o comportamento adotado por estudantes mato-grossenses frente as condições de saneamento básico para evitar as verminoses. A pesquisa configura-se como descritiva e exploratória ocorrida no quarto bimestre de 2019. Foram investigados 20 estudantes do $7^{\circ}$ Ano do Ensino Fundamental de uma escola pública mato-grossense, de Vila Rica/MT. Como instrumento de coleta de dados foi utilizado um questionário impresso, contendo 9 questões abertas que indagaram desde os conceitos de verminose e saneamento básico, as condições que enfrentam, até os hábitos que adotam frente a problemática. A maioria dos estudantes conceitua verminose como doença/ infecção causada por vermes, também acreditam que o saneamento básico é condição fundamental para garantir qualidade de vida. Para evitar verminoses, os estudantes evidenciaram os cuidados com o próprio corpo, como o banho diário, lavar mãos antes das refeições e demais cuidados com a higiene pessoal. $\mathrm{O}$ estudo possibilitou identificar

1 Graduação em Licenciatura em Ciências Biológicas e Bacharel em Ecologia (Centro Universitário de Várzea Grande). Especialização em Ensino de Biologia (Universidade Candido Mendes). Professora efetiva na Escola Estadual Professora Maria Esther Peres onde ministra as disciplinas de ciências e biologia para o Ensino Fundamental e Médio. Membro do Grupo de Pesquisa Ensino de Ciências e Matemática no Baixo Araguaia (EnCiMa).

2 Graduanda de Biologia pela Universidade do Estado de Mato Grosso (UNEMAT).

3 Graduação em Química Licenciatura Plena (UNISC) e em Licenciatura em Física (UNEMAT). Especialização em Orientação Educacional (DOM ALBERTO) e em Relações Raciais e Educação na Sociedade Brasileira (UFMT). Mestrado em Ensino (UNIVATES) e Doutorado em Educação em Ciências: Química da Vida e Saúde (UFRGS). Professor de Química no Departamento de Ensino do IFMT Campus Confresa. Membro do Grupo de Pesquisa Ensino de Ciências e Matemática no Baixo Araguaia (EnCiMa). 
a situação em que vivem e o comportamento que adotam frente ao problema. O debate iniciado por meio dessa investigação precisa continuar.

Palavras-chave: Doenças tropicais. Saúde. Verminose.

\section{INTRODUÇÃO}

Os problemas urbanos afetam diretamente a qualidade de vida das pessoas mais carentes, entre inúmeros problemas, temos um que se destaca nesse cenário: a ausência de saneamento básico no território brasileiro. Com este problema temos a ocorrência de doenças tropicais negligenciadas (DTNs). Mas o que vem a ser doenças tropicais negligenciadas? De acordo com a Organização Mundial da Saúde (OMS), são as doenças correlatas com a pobreza. Conforme Zicker (2019, p. 8), "As doenças tropicais negligenciadas são definidas como um grupo de doenças infecciosas crônicas promotoras da pobreza, que ocorrem principalmente em áreas rurais e áreas urbanas pobres de países de baixa e média renda". Os episódios dessas doenças caracterizam um país desenvolvido pelo seu impacto na vida, saúde e desenvolvimento da sociedade.

De acordo com a citação supracitada é possível constatar que as doenças tropicais negligenciadas são aquelas que dependem simplesmente de aporte financeiro de recursos para serem combatidas, que atingem os mais vulneráveis e ao mesmo tempo, contribuem para o aumento das desigualdades sociais. As principais doenças negligenciadas no Brasil de acordo com o Ministério da Saúde são as seguintes: doença de Chagas, esquistossomose, hanseníase, filariose linfática, leishmaniose tegumentar, leishmaniose visceral, oncocercose, raiva humana, tracoma (BRASIL, 2018).

Essas doenças são diversificadas do ponto de vista médico e constituem um grupo com características comuns, uma vez que todas estão fortemente associadas à pobreza, se disseminam em ambiente empobrecidos e todas sobrevivem melhor em ambientes tropicais, onde tendem a coexistir. Muitas delas têm causado sofrimento a humanidade há séculos. Entre elas destacamse as verminoses que ainda persistem em nosso meio e compõem uma questão epidemiológica de caráter emergencial, pois anualmente acomete muitos indivíduos.

De acordo com Zicker (2019, p.13), em 2015, o Ministério da Saúde confirmou que há 5.570 municípios com mais garantias de serem endêmicos de doenças negligenciadas. Foram identificados 104.476 casos novos de DTNs, sendo registrados os maiores números nas regiões Norte e Nordeste; 7.786 mortes por diferentes infecções foram registradas principalmente nas regiões Centro-Oeste, Sudeste e Nordeste. As estimativas são de que existem 26 milhões de pessoas sob risco de serem contaminadas por DTNs. 
Sendo os mais vulneráveis, as crianças estão mais sujeitas a diversas doenças parasitárias e entre elas, se destacam as verminoses, devido às más condições de higiene e à dificuldade de acesso ao saneamento básico.

Ao trazer esta temática para a escola é necessário fazer uma reflexão de cunho social principalmente acerca da vida dos estudantes e o conhecimento que possuem a respeito principalmente, quanto a profilaxia. Com essa abordagem educacional, busca-se preservar a saúde do estudante, bem como a saúde coletiva, por meio de noções de higiene pessoal e saneamento básico, garantindo assim, o direito à vida e à dignidade humana, bem como o pleno exercício da cidadania. Na perspectiva de Freire (1977), a educação não deve ensinar apenas a leitura das palavras, mas principalmente a leitura do mundo.

Levantar este debate na escola, por meio de dados da comunidade local, é uma necessidade, pois possibilita à escola desempenhar seu papel no sentido de sensibilizar o estudante quanto à promoção da saúde pública, haja vista que algumas medidas profiláticas são de aplicabilidade individual, e muitas vezes o estudante, oriundo de família com baixo grau de escolaridade e condições precárias de moradia, não tem acesso.

Além disso, o município de Vila Rica/MT, local onde foi desenvolvida a pesquisa, apresenta o seguinte cenário: no início da década de 80 , a região formada por floresta passa a ser colonizada por imigrantes provenientes de diversas regiões do pais, entre elas, Centro-Oeste, Sul e Norte, que em seguida passam a desmatar a região e instalar suas casas. Mesmo com uma ampla extensão territorial, as famílias foram se aglomerando em uma vila, posteriormente estruturada e planejada, tornando-se a sede do município. Assim, a cidade tem aspectos urbanísticos planejados, além de uma economia considerável. Embora não tenha sido industrializada, a pecuária se destaca frente ao cenário nacional tendo um dos maiores rebanhos do país. Uma análise em linhas gerais permite identificar, um território organizado, no entanto, um aspecto não foi levado em conta no ato do planejamento, o saneamento básico ausente na área urbana acarreta inúmeros problemas de saúde à população.

O presente estudo objetiva analisar o comportamento adotado por estudantes de uma escola pública mato-grossense frente às condições de saneamento básico, para evitar as verminoses e deste modo, desenvolver na escola uma reflexão acerca da importância de atitudes voltadas à promoção de saúde pública.

\section{REFLEXÕES TEÓRICAS}

O processo de urbanização consiste em uma diáspora do homem do campo, que vai para a cidade em busca de conseguir melhores condições econômicas, no intuito de sustentar sua família. Devido à falta de políticas públicas voltadas à agricultura familiar e à permanência do mesmo no campo, ele vai para a cidade e lá é obrigado a conviver com novos desafios impostos 
pelo novo estilo de vida, percebendo as desigualdades sociais acentuadas, pois, na cidade ele nem sempre consegue condições adequadas de moradia, tampouco tem acesso ao saneamento básico, algo que é fundamental para assegurar sua saúde e de seus familiares.

Segundo dados do IBGE (2017), o número de municípios emancipados no Brasil que em 1960 era de 2.765, com uma população de 71 milhões e taxa de urbanização de $45 \%$, saltou para 5.570 em 2013, com uma população de aproximadamente 191 milhões e grau de urbanização de $84,4 \%$.

Costa (2018, p. 39) define que sanear tem origem do latim: sanun, tornar saudável, tornar habitável, higienizar, limpar. Logo, conclui-se saneamento como um conjunto de medidas a fim de preservar as condições do meio ambiente, prevenir doenças e melhorar as condições de saúde da população.

Diante desta realidade apresentada, foi necessário pensar medidas de saneamento ambiental, pois o mesmo compreende um conjunto de medidas adotadas que visam garantir a qualidade ambiental visando também assegurar a qualidade de vida da comunidade nesse sentido, o saneamento ambiental é caracterizado por Brasil (2004, p.14) como:

[...] o conjunto de ações socioeconômicas que têm por objetivo alcançarníveis deSalubridade Ambiental, por meio de abastecimento de água potável, coleta e disposição sanitária de resíduos sólidos, líquidos e gasosos, promoção da disciplina sanitária de uso do solo, drenagem urbana, controle de doenças transmissíveis e demais serviços e obras especializadas, com a finalidade de proteger e melhorar as condições de vida urbana e rural.

Visando estender as garantias universais à qualidade de vida, na perspectiva de atender metas estabelecidas pela Agenda 21, um instrumento elaborado pela Organização das Nações Unidas (ONU), envolvendo quase todos os países do mundo. Com vista a balizar medidas adotadas em relação à preservação ambiental e qualidade de vida, no Brasil, em 2007 foi criada a Lei Nacional do Saneamento ${ }^{\circ} 11.445$, de 05/01/2007, que tem como intuito, criar estratégias para promover a universalização dos serviços de saneamento, estendendo o serviço a toda sociedade inclusive, ações de gestão, visando o controle das medidas adotadas. No ano de 2016 esta lei foi substituída pela Lei $\mathrm{n}^{\mathrm{o}} 13.308 / 2016$.

As leis supracitadas visam a proteção do ambiente, haja vista a contaminação ambiental como porta de entrada para diversas doenças. Uma vez que somos interligados, é necessário fazer uma correlação entre a mesmas, contemplando a ausência de saneamento básico, a incidência de parasitoses e a educação ambiental. Esse tripé é fundamental para que possa haver mudança neste cenário, como afirma Reigota (2009, p. 14): 
A educação ambiental deve procurar favorecer e estimular possibilidades de se estabelecer coletivamente uma "nova aliança" (entre os seres humanos e a natureza e entre nós mesmos) que possibilite todas as espécies biológicas a sua convivência com dignidade.

Além disso, a sociedade reage ao mercado de forma utilitarista e desta forma, dificulta a formação escolar do cidadão, por isso, Leff (2011) defende que a educação como processo de construção do saber, envolva os aspectos socioambientais e as mudanças climáticas. A relevância disto, torna possível compreender que os estudantes possuem em mente a compreensão de que, as medidas de prevenção às verminoses devem ser aplicadas somente de forma individual sem qualquer prejuízo as questões de saneamento.

Em 2015, o município de Mariana (MG), presenciou um grande impacto ambiental com o rompimento da Barragem Fundão, que causou a morte de 19 pessoas (SAMARCO, 2015). Este conflito também derivou na morte de peixes, a mata ciliar foi destruída e completamente coberta de lama e a alteração no $\mathrm{pH}$ do solo não permitiu mais o desenvolvimento de espécies vegetais da região. Esses impactos causaram aumento em doenças relacionadas à saúde humana, ou seja, tudo que for agregado ou retirado da natureza será refletido na sociedade.

Devido a este acidente ambiental algumas regiões ficaram negligenciadas e ainda hoje se elaboram políticas para corrigir o impacto (SAMARCO, 2015). O desastre no ambiente altera o estilo de vida, ocasionando estresse e reduções na atuação do sistema imune. Isso pode levar as pessoas a ficarem mais suscetíveis a doenças, uma vez que os vetores hospedeiros terão maior contato e, consequentemente, aumento das possibilidades de contaminação.

Nesse sentido, a escola precisa confrontar o estudante com a própria realidade e proporcionar subsídios para que o mesmo possa questionar sobre sua posição na sociedade e tenha condições de buscar igualdade social, neste sentido a escola cumprirá seu papel, como propõe Freire (1979), ao afirmar que: para que o sujeito lute pela justiça social faz-se necessária uma educação crítica.

Esse tipo de educação é aquele voltado a fazer o indivíduo questionar sua realidade, é capaz de conduzir o estudante a uma tomada de consciência principalmente nas questões que tangem à qualidade ambiental, uma vez que os recursos ambientais pertencem a todos os seres viventes e as gerações que ainda virão habitar esse planeta, neste sentido, passa a encampar a luta pela defesa do meio ambiente e pela qualidade de vida (REIGOTA, 2009).

A educação ambiental precisa ser dialógica, na qual professores e estudantes sejam capazes de mirar para o mesmo horizonte e traçar metas que sejam acessíveis no sentido de transformar as velhas práticas existentes, uma vez que as mesmas não estão de acordo com a expectativa da sociedade, é preciso que haja transformação. Para Paulo Freire (1987) a educação precisa 
ser dialógica, sempre associada a uma ação, para que se torne práxis, de modo que não seja apenas mero ativismo, pois "ao alcançarem, na reflexão e na ação em comum, este saber da realidade, se descobrem como seus refazedores permanentes" (FREIRE, 1987, p. 32).

Outro dilema da Educação Ambiental é a necessária conservação do meio ambiente, principalmente nos atuais dias de tecnologia e industrialização, o que deve ser incorporado como prioridade na escola. Com o mercado cada vez mais consumista, as medidas profiláticas precisam ser voltadas para preservar o ambiente. Quando afirmamos preservar, pensamos em um todo, que compreende saúde, melhores condições de vida, lazer e social. $\mathrm{O}$ termo desenvolvimento sustentável define que o desenvolvimento deverá suprir as necessidades da população atual sem agredir as populações futuras. As palavras de Leff (2011, p. 222) contemplam a grandiosidade desse desafio:

Os objetivos do desenvolvimento sustentável exigem uma mudança nos valores que orientam o comportamento dos agentes econômicos e da sociedade em conjunto, além da transformação do conhecimento e da inovação de tecnologia para resolver os problemas ambientais.

Este desafio norteia a relação entre saneamento básico e as verminoses. Além disso, há muitos anos que o ser humano se relaciona com o meio ambiente e essa interação resulta em impactos ambientais que podem ser químicos, físicos e biológicos, considerados positivos ou negativos de acordo com os resultados causados.

Com a Revolução Industrial, ocorreu o êxodo rural de maneira mais acentuada, o que levou um número significativo de pessoas a habitar os centros urbanos, em busca de emprego e melhoria de vida. Além disso, as indústrias exploraram mais recursos naturais, sem contar que provocou a contaminação industrial. Poluíram a água, o ar, o solo, cortaram árvores e tudo isso facilitou o surgimento de doenças. Esse assunto ainda é um tabu a ser trabalhado nas escolas de Mato Grosso e pouco se aborda sobre o tema. Morel (2006) considera que as verminoses são casos de doenças negligenciadas mais importantes e são enfermidades totalmente associadas às questões de saneamento básico.

Verminoses podem ser definidas como doenças causadas por meio de parasitas intestinais também conhecidas como parasitoses intestinais (CHIEFF, 2003, p. 41). As infecções parasitárias dos intestinos, refletem as condições de vida de diferentes comunidades, principalmente, apontam a ausência de saneamento básico. Ainda de acordo com o autor supracitado, os modos de ocorrência e a frequência com que parasitoses intestinais são encontradas em determinadas localidades dependem de interações complexas entre hospedeiros, parasitas e ambiente. 


\section{PROCEDIMENTOS METODOLÓGICOS}

O presente estudo se caracteriza como uma pesquisa descritiva e exploratória. Conforme Gil (2010), uma pesquisa deste tipo possibilita levantar características, de populações, fenômenos ou experiências vivenciadas, ou seja, serve para ilustrar o pensamento dos investigados e assim analisar tais informações subjetivamente.

Esse estudo foi desenvolvido na Escola Estadual Professora Maria Esther Peres, localizada no município de Vila Rica/MT, distante $1.264 \mathrm{~km}$ da capital Cuiabá/MT. Sua realização ocorreu no segundo semestre de 2019. O público envolvido foi constituído por 20 estudantes do $7^{\circ}$ ano D do Ensino Fundamental, devidamente matriculados no turno vespertino.

Após apresentação do objetivo da pesquisa, a gestão da escola emitiu Carta de Anuência autorizando a realização da pesquisa. Cabe ressaltar que todos os pais dos estudantes aceitaram e assinaram um termo no ato da matrícula no qual expressam seu consentimento para que seus filhos participem de todas as atividades da escola, inclusive de pesquisas com finalidade educativa.

O desenvolvimento da atividade teve o intuito de identificar a situação e o comportamento adotado por estudantes de uma cidade mato-grossense frente às condições de saneamento básico para evitar as verminoses. A atividade aconteceu num período de duas aulas, sendo que inicialmente os estudantes tiveram acesso a textos que abordavam contextos relacionais entre ecologia, saneamento básico e incidência de verminoses.

A proposta constituiu em conhecer a concepção dos estudantes acerca das principais doenças causadas por verminoses e a importância do saneamento básico e a higiene pessoal. Os estudantes receberam um questionário com nove perguntas abertas. Para garantir o anonimato dos envolvidos e facilitar a apresentação dos resultados, as respostas foram agrupadas por semelhança e apresentadas em gráficos de maneira a não identificar o estudante que a emitiu.

A metodologia de análise de dados utilizada neste estudo é análise de conteúdo do tipo temática e frequencial. Segundo Bardin (2012), a operação de categorizar pode ser considerada como o ato de classificar os elementos constitutivos de uma mensagem e isso é possível quando as mensagens são diferenciadas e reagrupadas segundo o gênero.

As três categorias pré-estabelecidas por meio da elaboração do questionário foram: conceitos de verminose e saneamento básico, condições que enfrentam e hábitos que adotam frente a problemática. Essas categorias foram discutidas com a teoria utilizada no referencial teórico, além do posicionamento dos autores quanto a esses resultados obtidos. 


\section{RESULTADOS E DISCUSSÃO}

A primeira categoria - conceitos de verminose e saneamento básico-, foi analisada a partir das três primeiras perguntas, que foram: 1) Explique o que são verminoses? 2) Já teve alguma verminose? 3) O que você entende por saneamento básico e qual é a sua importância para a população? O primeiro questionamento visou levantar o conceito que os estudantes possuem sobre o que são verminoses. As respostas foram tabuladas e seguem ilustradas na Figura 1.

Figura 1: Conceito de verminoses.

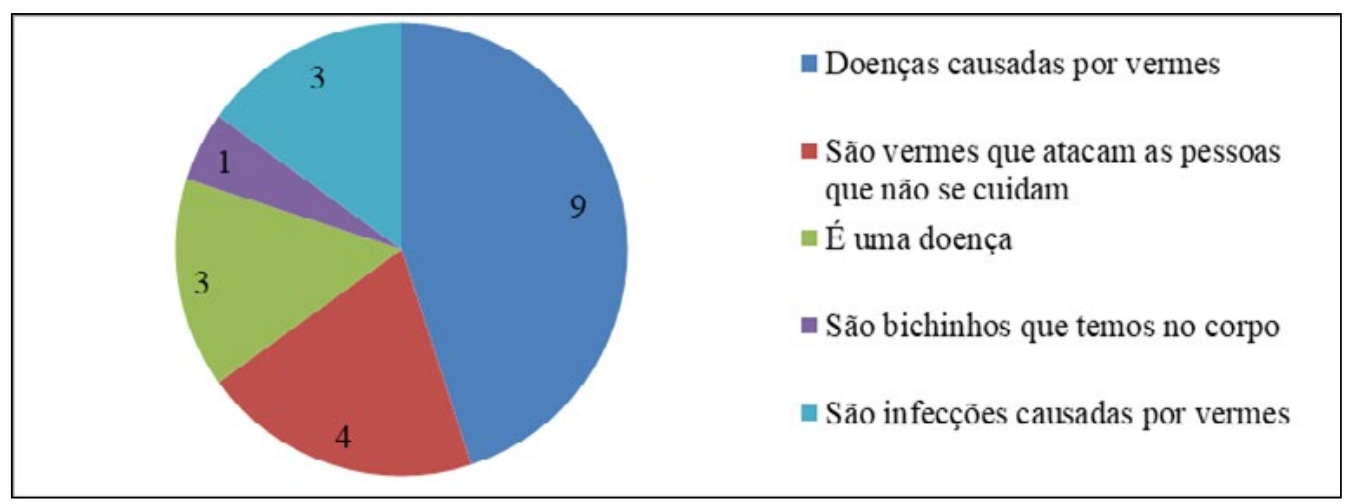

Fonte: Dados coletados na pesquisa (2019).

De acordo com os resultados, os estudantes possuem um conhecimento do que são as verminoses, pois a maioria associa verminoses a "doenças causadas por vermes" e a "infecções causadas por vermes". O que se nota é que eles compreendem com facilidade que as verminoses são causadas por vermes parasitas que se alojam no nosso organismo. Essa compreensão comunga com a definição de Chieff (2003), de que as verminoses, ou parasitoses intestinais, são doenças causadas por vermes.

Segundo Dias (2004, p. 15): “a sociedade humana foi empurrada por padrões de consumo insustentáveis, impostos por modelos insanos que afugentaram as populações camponesas e as cidades se tornaram superpovoadas, imersas em problemas crônicos de saneamento e serviço"

Um segundo questionamento foi sobre se os estudantes já tiveram algum tipo de verminose. A Figura 2 ilustra a síntese de suas respostas. 
Figura 2: Ocorrência de verminoses entre os estudantes.

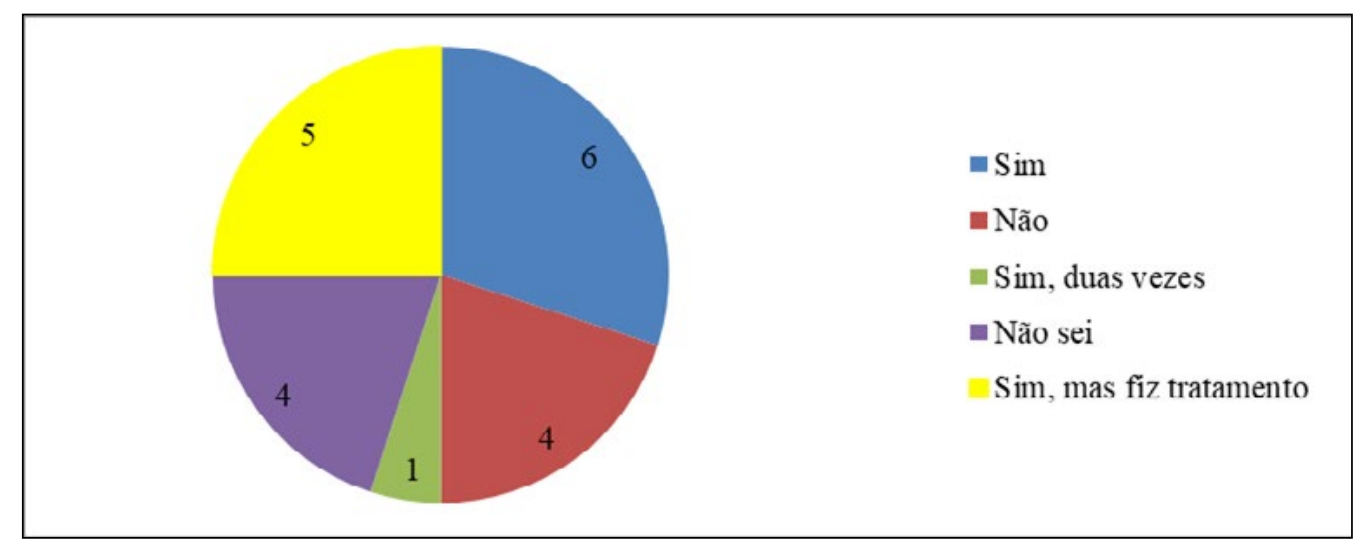

Fonte: Dados coletados na pesquisa (2019).

Os dados também permitem observar que alguns estudantes não sabem se tem ou já tiveram alguma doença relacionada a verminoses. Devido a isto, consideramos importante o ensino de Educação Ambiental, na compreensão de que o meio ambiente é visto como um todo, a necessidade de hábitos de higiene e saneamento básico. $\mathrm{O}$ aparecimento dessas parasitoses está totalmente relacionado a determinado local e interação entre hospedeiro, meio ambiente e parasita (MOREL, 2006).

Existe um elo entre Ensino, Educação Ambiental e Saúde e nunca foi tão necessário modificar paradigmas acerca do saneamento básico como nos dias atuais. No Brasil, projeta-se uma estimativa de que $36 \%$ da população seja afetada por verminoses. Portanto, há uma quantidade de pessoas que por vezes são contaminadas por parasitas, mas não buscam a rede pública de saúde. Entre os estudantes que corroboraram com a pesquisa deste trabalho alguns desconheciam já ter contraindo doenças parasitárias.

O terceiro questionamento abordou sobre o que os estudantes entendem por saneamento básico e qual importância dele para a população. Os estudantes se manifestaram e suas respostas foram tabuladas e seguem ilustradas na Figura 3. 
Figura 3: Conceito e importância do saneamento básico.

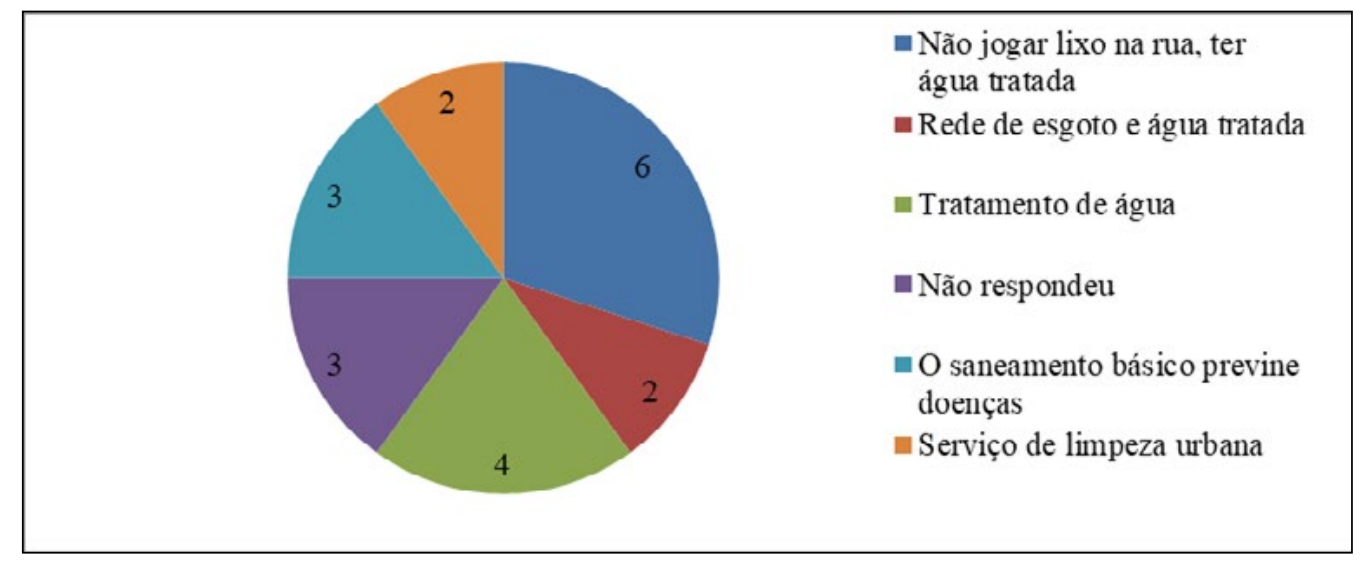

Fonte: Dados coletados na pesquisa (2019).

Este gráfico demonstra que os estudantes compreendem como saneamento básico um conjunto de ações e são capazes de associá-las com a qualidade ambiental e a qualidade de vida. As condições necessárias de saneamento afetam diretamente saúde, qualidade de vida e desenvolvimento de uma sociedade e é uma prerrogativa de países desenvolvidos. A principal característica da ausência de saneamento básico é o alto índice de endemicidade de doenças negligenciadas, principalmente por aquelas famílias de áreas urbanas menos favorecidas de recursos (ANVISA, 2007). Infelizmente essas doenças geralmente acontecem em regiões mais empobrecidas e menos avantajadas de recursos, como periferias, interiores, sendo muitas vezes as agravadas de pobreza intensa (HOTEZ et al., 2006).

A segunda categoria (condições que enfrentam) foi analisada a partir de três outras perguntas: 4) Qual é o destino do esgoto sanitário de sua residência? 5) Na sua comunidade, há o fornecimento de água tratada e rede de esgoto para os moradores? 6) Explique as formas de transmissão das verminoses? No quarto questionamento, os estudantes se manifestaram sobre o destino do esgoto de suas residências. As respostas foram tabuladas e seguem ilustradas na Figura 4. 
Figura 4: Destino do esgoto das residências dos estudantes.

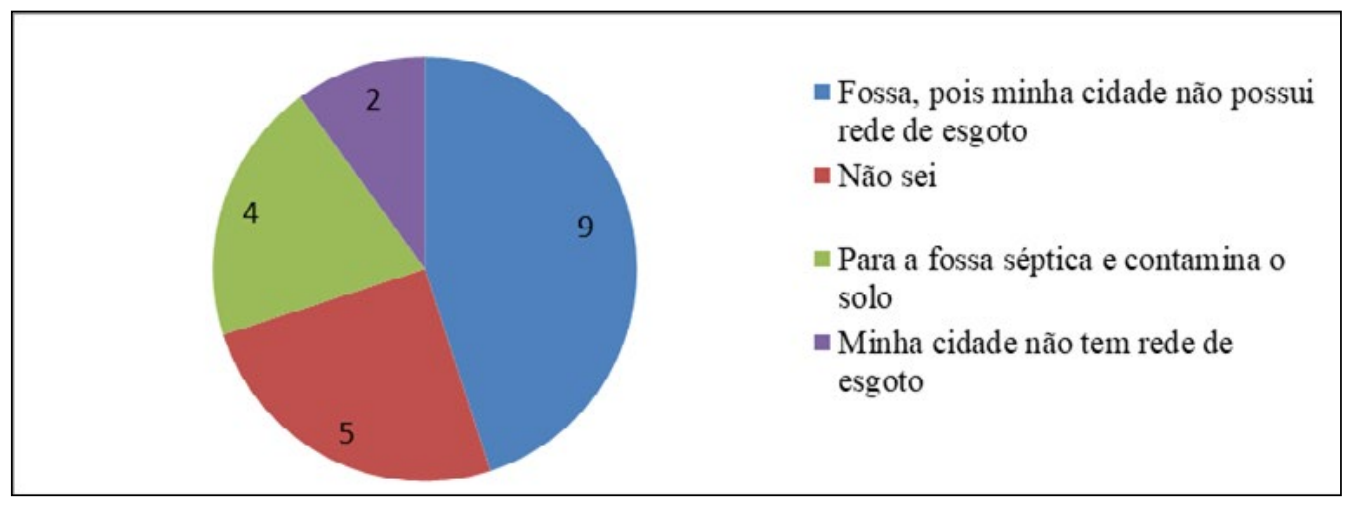

Fonte: Dados coletados na pesquisa (2019).

Devido à falta de rede de esgoto sanitário as moradias possuem fossas para destinar o esgoto sanitário. A localização correta seria há uma distância de 15 metros entre a fossa e o poço, mas algumas residências já tiveram mais de uma fossa dentro do quintal, levando à contaminação do lençol freático que fornece a água usada no cotidiano, aumentando o número de coliformes fecais e a infecção por verminoses na população.

Assim como Morel (2006) afirma, as verminoses e demais doenças negligenciadas estão totalmente relacionadas quando se trata de saneamento básico sendo que este é responsável por proporcionar as indigências mínimas à população. No Brasil, a Lei 11.445/2007 regulamenta o saneamento básico e dentro desta proposta antecipa políticas públicas de participação social. Comum a lei de saneamento básico existe a Política Nacional de Resíduos Sólidos (PNRS) que é uma Lei Federal no 12.305/2010 que prevê que todos os envolvidos no ciclo de vida de algum produto possuem responsabilidade sobre os resíduos que serão gerados desde a fabricação até o uso e descarte do mesmo (BRASIL, 1988).

O quinto questionamento se refere à existência de fornecimento de água tratada e rede de esgoto para os moradores na comunidade na qual estão inseridos. As respostas foram tabuladas e seguem ilustradas na Figura 5. 
Figura 5: Fornecimento de água tratada e rede de esgoto.

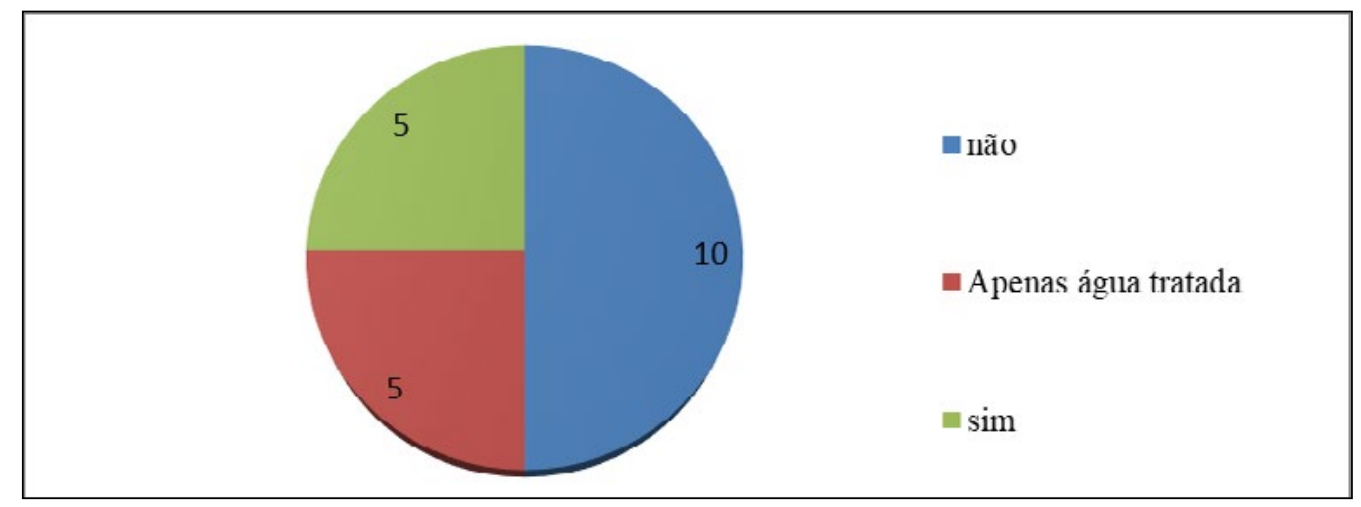

Fonte: Dados coletados na pesquisa (2019).

A falta de água tratada é uma realidade nacional e uma das principais causas de doenças parasitárias endêmicas. A principal causa da poluição da água é a destinação incorreta de lixos domésticos e industriais. Existem muitos programas de controle relacionados à erradicação de lixões, como o Programa Nacional de Lixão Zero (MMA, 2019), que propõe métodos de construção de aterros sanitários e coleta seletiva, mas infelizmente são pouco difundidos. Pelo visto, essa condição ideal está longe de acontecer. O que se observa em grande parte do país é o contato diário com esgotos abertos ou a falta de esgotos adequados e lixões, além da falta de condições de higiene, tudo isso contribui para causar verminoses. O município de Vila Rica/MT é um exemplo desta realidade, pois ainda possui lixão, uma diversidade de córregos próximos à comunidade com restos de lixo doméstico, além de áreas de preservação ambiental sendo danificadas e poluídas por resíduos sólidos.

O sexto questionamento foi sobre quais formas de transmissão/ contaminação das verminoses os estudantes conheciam. As respostas seguem ilustradas na Figura 6. 
Figura 6: Formas de transmissão/contaminação das verminoses.

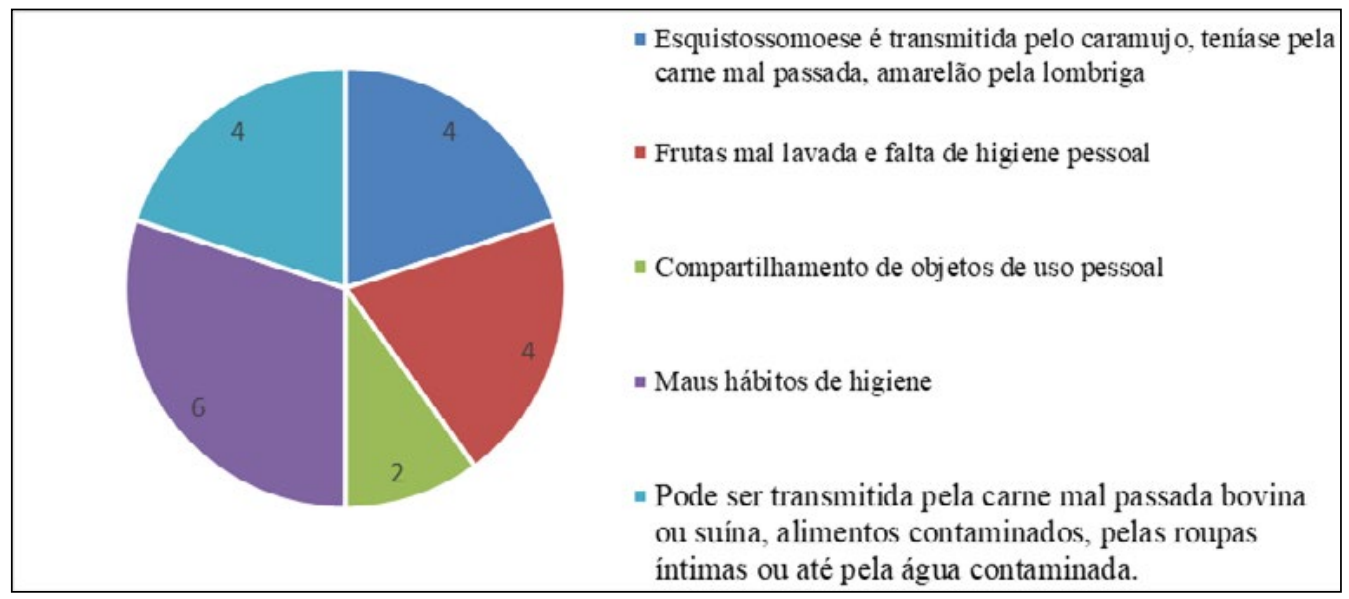

Fonte: Dados coletados na pesquisa (2019).

Um fato a ser considerado é que doenças como as verminoses prejudicam o desenvolvimento físico, social e cognitivo do ser humano, principalmente em crianças. Os primeiros meses de vida podem ser considerados o período de maior risco de contaminação, pois os bebês levam tudo à boca para explorar. Também na primeira infância e na adolescência é preciso ter cuidado, pois muitos descuidam da higiene.

A dificuldade se encontra também na aplicação das medidas profiláticas para evitar a contaminação. É visto que o problema não é somente a falta de informação entre pais, filhos e comunidade, pois mesmo sabendo a importância de lavar as mãos e a comum orientação sobre cuidar e cozinhar corretamente os alimentos, alguns desses métodos são esquecidos. As políticas públicas voltadas para o saneamento básico possuem uma boa redação, mas na prática, mesmo em cidades onde os métodos são utilizados, nem sempre são elaborados corretamente. Um exemplo, são os aterros mal ordenados que acabam danificando o lençol freático e a coleta seletiva, onde boa parte dos resíduos não é descartada de forma regular.

Outra problemática observada em Vila Rica, mas que não difere da maioria das cidades brasileiras, é a falta de projetos para coleta seletiva do lixo. Também existem muitas moradias localizadas próximas a terrenos baldios, córregos e lagos, que as torna suscetíveis a contaminação por doenças. Os locais abandonados são destinos preferidos para pessoas com hábitos jogar lixos. De acordo com Leff (1998), o neoliberalismo econômico influencia na desvalorização dos recursos ecológicos e do próprio meio ambiente.

A terceira e última categoria - hábitos que adotam frente a problemática-, foi analisada a partir dos três últimos questionamentos: 7) Explique, quais as medidas que devem ser praticadas para prevenir as verminoses? 8) Quanto aos 
aspectos preventivos, que hábitos de higiene pessoal fazem parte de uma vida saudável? 9) Que hábitos saudáveis serão incorporados por você diariamente? As respostas para a pergunta 7 foram tabuladas e seguem ilustradas na Figura 7.

Figura 7: Medidas para prevenir as verminoses.

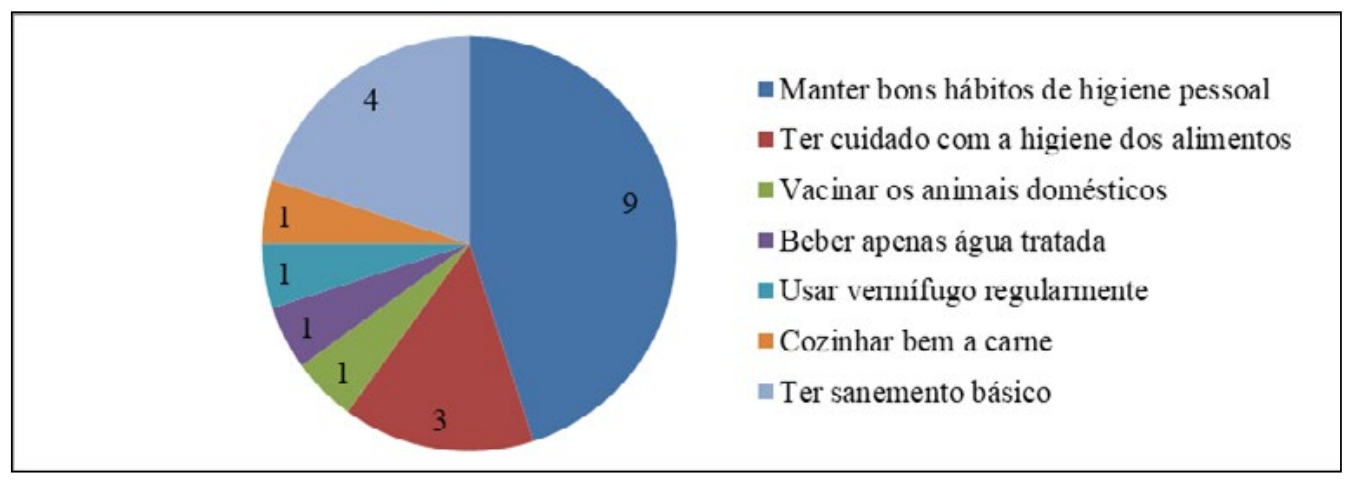

Fonte: Dados coletados na pesquisa (2019).

O oitavo questionamento abordou quais os aspectos preventivos que podem ser adotados para evitar as verminoses por meio de hábitos de higiene pessoal. As respostas dos estudantes foram tabuladas e seguem ilustradas na Figura 8.

Figura 8: Aspectos preventivos por meio de hábitos de higiene pessoal.

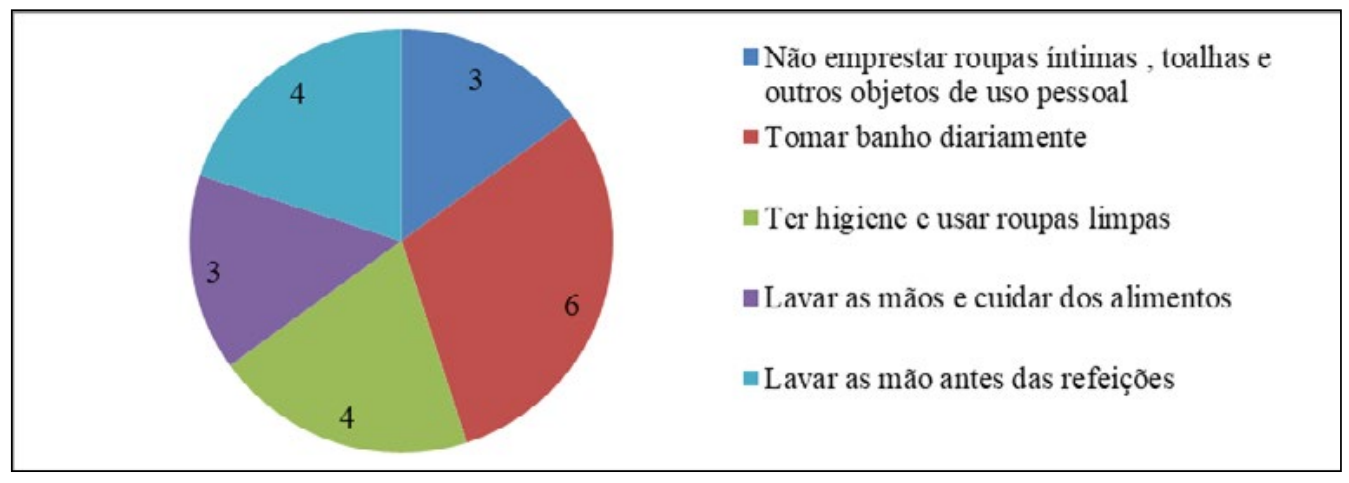

Fonte: Dados coletados na pesquisa (2019).

A importância da Educação Ambiental dentro do ambiente escolar causa impactos muito mais abrangentes. O pensamento de Freire (1977) compreende a importância das relações familiares e afetivas, onde o ser humano somente alcança total desenvolvimento quando interage com pessoas e meio ambiente. As ações humanas na sociedade acarretam resultados que atingem diretamente 
a população. Desde muitos anos essas ações são demonstradas como um reflexo no mundo em que vivemos devido aos modos de vida dos nossos antepassados, essas ações podem ser positivas ou negativas. Podemos citar como negativas a falta de água potável, falta de tratamento de esgoto e aumento de resíduos sólidos.

No nono e último questionamento, os estudantes se manifestaram sobre quais hábitos de higiene adotam diariamente para evitar as verminoses. As respostas foram tabuladas e seguem ilustradas na Figura 9.

Figura 9: Hábitos de higiene adotados diariamente.

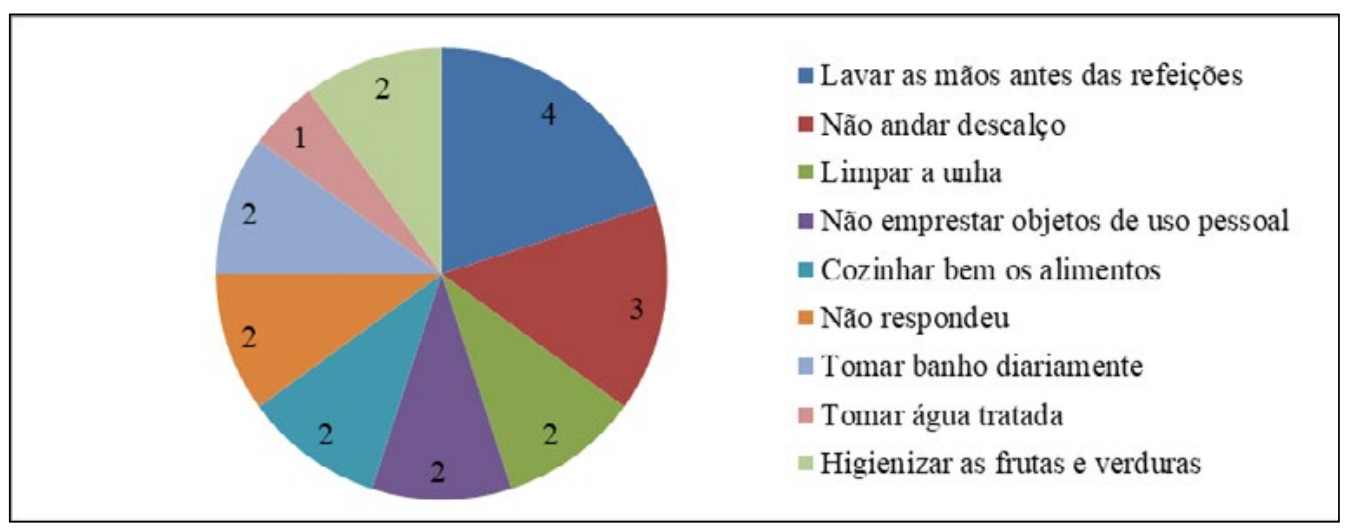

Fonte: Dados coletados na pesquisa (2019).

De acordo com esse último questionamento, ao serem indagados sobre quais hábitos serão incorporados ao seu cotidiano a partir desse estudo, percebe-se que os estudantes destacaram que é fundamental ter bons hábitos de higiene e o cuidado com o preparo e manipulação dos alimentos.

O ambiente escolar e seus sujeitos podem ser protagonistas na formação de cidadãos interessados no meio em que vivem, de forma que possa ser formada uma cadeia ambiental na prevenção de zonas de lixo e áreas de contaminação por parasitas. Assim, o estudante tem o primeiro contato na escola e leva para o mundo.

\section{CONSIDERAÇÕES FINAIS}

$\mathrm{O}$ estudo possibilitou identificar a situação em que vivem e o comportamento que os estudantes adotam frente aos problemas que a falta de saneamento básico e de educação ambiental provocam em sua realidade social. Quando compreendemos que o município de Vila Rica é pobre em saneamento básico reconhecemos que alguns hábitos são inconstantes e se torna evidente, por exemplo, como o uso de fossas para destino do esgoto sanitário auxilia na 
disseminação de doenças parasitárias, visto que boa parte da população utiliza poços artesianos e cisternas para fornecimento de água.

Portanto, tratar sobre o assunto verminoses dentro da sala de aula contribuiu para clarear a realidade. A disseminação de ideias e informações corretas foram benéficas no que diz respeito aos hábitos diários de higiene e cuidado do meio ambiente, o que pode vir a fazer diferença nos hábitos do estudante e seus familiares.

A partir da aula, a maioria dos estudantes conceituaram verminoses associando aos cuidados com a higiene e, ao saneamento básico, como condição fundamental para garantir a diminuição da contaminação de doenças negligenciadas. Dessa forma, fica evidente a importância de propor situações de aprendizagem que abordem a temática verminoses, pois a participação e o envolvimento dos estudantes indicam que de fato é um assunto relevante para ser estudado, ainda mais por envolver como proceder nessa realidade local para não ser acometido desse tipo de doença.

A curiosidade dos estudantes foi despertada, bem como a necessidade de modificar hábitos e práticas pessoais e públicas em relação ao saneamento básico. Portanto faz-se necessário que o estudo e as discussões sobre a temática continuem ocorrendo, pois é uma maneira de esclarecer e proporcionar que os estudantes se apropriaram desse conhecimento.

\section{REFERÊNCIAS}

AGÊNCIA NACIONAL DE VIGILÂNCIA SANITÁRIA (ANVISA). Resolução RDC $n^{\circ} 28$, de 4 de abril de 2007. Dispõe sobre a priorização da análise técnica de petições, no âmbito da Gerência-Geral de Medicamentos da ANVISA, cuja relevância pública se enquadre nos termos desta Resolução.

BARDIN, Laurence. Análise de conteúdo. São Paulo: Edições 70, 2012.

BRASIL. Ministério da Saúde. Secretaria de Vigilância em Saúde. Doenças negligenciadas no Brasil: vulnerabilidade e desafios. Brasília: Ministério da Saúde, 2018. Disponível em: <http://bvsms.saude.gov.br/bvs/publicacoes/ saude_brasil_2017_analise_situacao_saude_desafios_objetivos_desenvolvi-mento_ sustetantavel.pdf>

BRASIL. Fundação Nacional de Saúde. Manual de saneamento. 3. ed. rev. Brasília: Fundação Nacional de Saúde, 2004.

BRASIL. Constituição Federal (1988). Disponível em: http:/ /www.planalto.gov.br/ ccivil_03/_ato2007-2010/2010. Acesso em: 11 abr. 2020.

BRASIL. Lei $\mathbf{N}^{\circ} \mathbf{1 1 . 4 4 5} \mathbf{n}^{0} \mathbf{1}$, de 5 de janeiro de 2007. Capítulo I - DOS PRINCÍPIOS FUNDAMENTAIS. Art. 2. Disponível em: http://www.planalto.gov.br/ccivil_03/_ Ato2007-2010/2007/Lei/L11445.htm. Acesso em: 11 abr. 2020. 
CHIEFFI, Pedro Paulo; AMATO NETO, Vicente. Vermes, verminoses e a saúde pública. Ciência e Cultura, São Paulo, v. 55, n. 1, p. 41-43, 2003.

COSTA, Aroldo Rereira. Educação Ambiental e sua Relação com o Saneamento Básico e a Saúde Pública no Município de Porto Nacional Tocantins. Dissertação de mestrado. São Paulo. Universidade Brasil. 2018.

DIAS, Genebaldo Freire. Educação Ambiental: princípios e práticas. 9. ed. São Paulo: Gaia, 2004.

FREIRE, Paulo. Pedagogia do oprimido. 4. ed. Rio de Janeiro: Paz e Terra, 1977.

GLOBO.COM (ed.). Verminose afeta 36\% da população; entre as crianças, mais da metade. Jornal Nacional. São Paulo. 17 jul. 2018. Disponível em: http:/ /g1.globo. com/jornal-nacional/noticia/2018/07/verminose-afeta-36-da-populacao-entrecriancas-mais-da-metade.html. Acesso em: 10 abr. 2020.

HOTEZ, P. J. et al. Incorporating a Rapid-Impact Package for Neglected Tropical Diseases with Programs for HIV / AIDS, Tuberculosis, and Malaria. PLoS Medicine, v.3, n.5, p. e102, 2006

IBGE. Porto Nacional: População 2014. Disponível em: http:/ / www.ibge.gov.br / cidades Acesso em: 11 abr. 2020.

LEFF, Enrique. Saber Ambiental: Sustentabilidade, Racionalidade, Complexidade, Poder. Petrópolis, RJ: Vozes, 1998.

LEONARD, Annie. A história das coisas da natureza ao lixo o que acontece com tudo que consumimos. Tradução Heloisa Mourão. Rio de Janeiro, Zahar. 2011.

MMA, Ascom. MMA lança Programa Nacional Lixão Zero. 2019. MINISTÉRIO DO MEIO AMBIENTE. Disponível em https:/ / www.mma.gov.br/informma/ item/15466-mma-lan\%C3\%A7a-programa-nacional-lix\%C3\%A3o-zero.html. Acesso em: 11 abr. 2020.

MESQUITA, B. Código florestal: quem tem razão? Disponível em:www.ambiente. sp.gov.br/arquivos.

MOREL, C. Inovação em saúde e doenças negligenciadas. Cadernos de Saúde Pública, v. 22, n. 8, p. 1522-1523, 2006.

ODUM, E. P. Ecologia. Rio de Janeiro: Interamericana, 1985.

REIGOTA, Marcos. O que é educação ambiental. 2. ed. revista ampliada -Brasiliense, 2009.

SAMARCO. Entenda o rompimento. 2015. Disponível em: https:/ / www.samarco. com/rompimento-de-fundao/. Acesso em: 11 abr. 2020.

ZICKER, Fabio. Doenças tropicais negligenciadas: uma agenda inacabada / Fabio Zicker, Priscila Costa Albuquerque, Bruna de Paula Fonseca e Fonseca. - Rio de Janeiro: Fundação Oswaldo Cruz, 2019. 